\title{
NUTRITIONAL STATUS, MACRO- AND MICRONUTRIENT DEFICIENCY IN CHILDREN WITH NEURODEVELOPMENTAL DISORDERS
}

\author{
Ruzha Pancheva-Dimitrova ${ }^{1}$, Albena Toneva ${ }^{1}$, Miglena Georgieva $^{2}$, \\ Desislava Konstantinova ${ }^{3}$, Stefka Petrova ${ }^{4}$ \\ ${ }^{1}$ Department of Hygiene and Epidemiology, Faculty of Public Health, \\ Medical University of Varna \\ ${ }^{2}$ Department of Pediatrics, Faculty of Medicine, Medical University of Varna \\ ${ }^{3}$ Department of Prosthetic Dentistry, Faculty of Dental Medicine, \\ Medical University of Varna \\ ${ }^{4}$ National Center of Public Health and Analyses, Bulgaria
}

\begin{abstract}
The nutritional status of children with neurodevelopmental disorders (NDDs) has a significant impact on their overall health and quality of life. Most of the scientific research, exploring NDD children's nutrition, has been dedicated to cerebral palsy $(\mathrm{CP})$ patients who are reported to suffer from malnutrition in $46 \%-90 \%$ of the cases. The etiology of malnutrition in children with NDD involves many underlying factors and can be contributed to both nutritional and non-nutritional factors. Obesity typically associated with mentally retarded children and children with genetic syndromes (e.g. Down syndrome) is nowadays less frequently observed. The energy needs of children with severe cases of central nervous system disorder differ from the energy requirements of normally developing children. The difference can be largely attributed to the interplay of several factors affecting the basal metabolic rate. The prevalence of malnutrition can induce or worsen respiratory failure as well as secondary immune deficiency, which in turn affects the prognosis of the underlying disease. Macronutrient deficiency in NDD children is commonly accompanied by micronutrient losses of folate, iron, magnesium, vitamin D, essential fatty acids, etc., which are crucial for a number of metabolic pathways. The lacking in any or all macro- and micronutrients may produce symptoms that are difficult to distinguish from the already present neurological disorder. This situation calls for a comprehensive evaluation and nutritional support for NDD children for an improved prognosis and quality of life, considering the current data and knowledge on the problem.
\end{abstract}

Keywords: cerebral palsy, malnutrition, micronutrient deficiency, neurodevelopmental disorder, nutrition, oral health

\author{
Address for correspondence: \\ Ruzha Pancheva-Dimitrova \\ Faculty of Public Health \\ Medical University of Varna \\ 55 Marin Drinov St \\ 9002 Varna \\ e-mail:ruja.pancheva@mu-varna.bg
}

Received: October 29, 2017

Accepted: June 8, 2018

\section{INTRODUCTION}

The nutritional status of children with a neurodevelopmental disorder (NDD) has a significant impact on their overall health and quality of life (1). Both malnutrition and over-nutrition of those children can generally lead to an increase in the need for medical care, and subsequently, to their reduced participation in educational and social activities. Malnutrition is commonly linked to impaired growth, 
reduced peripheral circulation, delayed wound healing, increased spasticity and irritability, dental and periodontal diseases. It is difficult to estimate the incidence of malnutrition in children with NDD due to the heterogeneous nature of neurological diseases. Most of the scientific research, exploring NDD children's nutrition, has been dedicated to cerebral palsy (CP) patients who are reported to suffer from malnutrition in $46 \%-90 \%$ of the cases (2). The etiology of malnutrition in children with NDD includes many underlying factors and can be contributed to both nutritional and non-nutritional factors. Among the nutritional factors, insufficient dietary intake is one of the main issues, often as a consequence of gastrointestinal disorders, including oral-motor dysfunction, gastroesophageal reflux and constipation. Among the non-nutritional factors, the type and severity of the neurological impairment, the degree of physical and cognitive impairment, and use of antiepileptic medication altogether play a key role in the determination of the nutritional status. Inadequate dietary intake leads to a delayed and suppressed immune response, short-term concentration, lack of motivation to participate in play and rehabilitation activities and poor prognosis of the underlying disease (3).

The aim of the present paper was to explore the current data and knowledge on the nutritional factors relevant to the nutritional status of children with NDD.

\section{Altered Energy Needs}

Changes in the energy needs (EN) are often observed among children with NDD and play an important role in their nutritional status. The energy needs of children with severe cases of central nervous system disorder differ from the energy requirements of normally developing children. The difference can be largely attributed to the interplay of several factors, affecting the basal metabolic rate (BMR), as well as to the fact that the physical status and characteristics of motor impairments (type, distribution and severity) affect the way, intensity of movements (choreoathetosis, dystonia) and muscle tone (hypertension, hypotension). The evidence present in scientific research indicates that BMR is significantly lower in most children with cerebral palsy compared to neurologically normal children. Conversely, children with atherosis exhibit similar or higher energy needs compared to normally developing children due to increased involuntary uncontrolled movements while at rest. The precise evaluation of the ENs is important yet hard to establish for the purpose of dietary intervention in NDD children. There are studies proposing a formula for calculating the energy needs of children with CP. The first method was developed by Krick et al. in 1992 (4), and a more recent equation was proposed by Rieken et al. (5) who developed two equations for pre-school age children with severe cases of CP and mobility. After basic calculations and corrections, each equation estimates the total energy expenditure taking into account the level of physical mobility, the level of activity of large muscle groups (gross motor activity) and the overall CP condition. Thirty-two pre-school children with CP aged 2.9 4.4 years participated in a study conducted by Walker et al. (6), using doubly labeled water method to determine energy requirements (ERs). A trend toward decreasing energy needs was observed with the deterioration of patients' mobility and the number of limbs involved. The greatest predictor of ERs was fatfree mass, then ambulatory status (walking ability).

\section{Malnutrition}

Reports on malnutrition prevalence among NDD children are scarce and depend on the type of diseases involved, the economic status of the country and the criteria for malnutrition. The reported incidence ranges from $34 \%$ (7) to 55\% (4) and even 90\% for CP children (2). More evidence is available on the suboptimal energy intake for children with NDD. A study conducted by Kilpinen-Loisa et al. (8) involved 54 children with motor disability (CP in 59\%, mean age 10.9 years), whose nutrient intake was analysed using three-day food diaries. The median energy intake was $76 \%$ of the recommendation and $<80 \%$ in $57 \%$ of children. Of the total energy intake, $17 \%$ was from protein, $32 \%$ from fat and 50\% from carbohydrates. Children with total energy intake $<80 \%$ of the energy requirements calculated with the specific formula for children with motor disability were more severely disabled and presented with significantly lower median height $\mathrm{z}$-scores compared to children with total energy intake $\geq 80 \%$ of the age-specific recommendations (Gross Motor Function Classification Scale (GMFCS) scores 3.8 vs. 3.0, $p=0.011$ and height $\mathrm{z}$-scores -1.5 vs. $-0.8, p=0.02$ ). 
Etiology of malnutrition in NDD children is multifactorial including both nutritional and nonnutritional factors. Among the nutritional factors, the main is represented by inadequate dietary intake as a consequence of gastrointestinal disorders including oral motor dysfunction, gastroesophageal reflux, and constipation (1).

The consequences of malnutrition are multifaceted. Inspiratory muscles demand energy for contraction (the expiratory process is passive); hence, energy deficiency in the respiratory muscles could cause or worsen respiratory failure, which in turn plays a role in the pathophysiology of the deteriorating pulmonary status characteristic in some NDD cases. Immune dysfunction may concurrently develop (impaired cell-mediated immune response, phagocytic activity, the complement system, secretory antibody synthesis, etc.). Such secondary immunodeficiencies lead to more frequent infections, which further aggravates malnutrition recovery.

Malnutrition also has impact on children's oral health, thus causing further under-nutrition $(9,10)$. This correlation may lead to the progression of some oral diseases, less resistance in microbial biofilm and less resistance of mucous and hard dental tissues (11). Protein-energy malnutrition (PEM) is known to affect the development of the oral cavity in childhood (12). Hypoplasia of the dental enamel, hypofunction of the salivary glands as well as saliva changes, subsequent to malnutrition, are the mechanisms by which malnutrition is associated with dental caries (13).

It is believed that by improving the nutritional status, either through increasing muscle strength, oral status, or by restoring immune competence, the clinical course of the neurodevelopmental disorder in children can be significantly enhanced (14).

\section{Obesity}

Obesity is more frequently observed in children with mental retardation, Prader-Willi syndrome, Down syndrome, spina bifida, Rett syndrome and less frequently in children with cerebral palsy. The obesity incidence ranges from $9.7 \%$ (7) to $35.7 \%$ (15). Obesity has proven to be a serious problem for children with NDD as it hinders unaided movement and compromises breathing.

There is convincing evidence that as far as the oral health of both NDD and healthy children is con- cerned, those overweight are at higher risk of developing dental erosion (erosio dentis) as opposed to children with normal weight. Erosio dentis is more likely to affect their anterior teeth (16). They are also more prone to developing oral complications, such as greater accumulation of dental plaque, periodontal bleeding, presence of deep periodontal pockets (17). There is also supporting evidence that as overweight and obese children mature earlier, their dental health deteriorates. The mean dental age acceleration for overweight subjects was $1.51 \pm 1.22$ years (18).

An extra weight gain of as much as $1.5-2.5 \mathrm{~kg}$ could possibly have a serious impact on children's physical activity such as climbing steps or even walking (14). Furthermore, researches have indicated that cardiovascular risk factors are more likely to be observed in children/adolescents with disabilities and obesity compared to children with disabilities having normal weight (19). The results showed that $42 \%$ of children/adolescents with spina bifida and obesity had either dyslipidemia or arterial hypertension, or both. In children/adolescents with disabilities, obesity is a major risk factor for the development and/ or aggravation of secondary conditions, arising from the underlying disease and impairment. Among such secondary conditions are fatigue and pain due to tension in the joints and muscles, resulting from the extra weight, which may lead to impaired mobility and even complete inability to walk for spina bifida or cerebral palsy patients (20). Moreover, their social isolation often leads to depression, which is particularly common in children with NDD and obesity (21). The chronic and secondary effects of obesity can contribute to a total loss of independence and thus further limit children's ability to move, play and find employment later on in life. Ultimately, such children's quality of life, already lower than their healthy peers', further deteriorates $(19,20)$.

\section{Micronutrient Deficiency}

Not only does inadequate dietary intake of macronutrients place children at risk of proteincalorie malnutrition/over-nutrition and slow/poor growth, but it may also give rise to deficiency of trace elements. Micronutrients are crucial for a number of metabolic pathways and the lack of any or all micronutrients may produce symptoms that are difficult to distinguish from the already present neurological 
disorder. The Dietary Reference Values (DRVs) include recommended/adequate dietary intake of micronutrients for Bulgarian population (22) which comply with the DRVs, adopted in Europe and the rest of the world, and do not differ for children with NDD and normally developing children (Table 1, Table 2).
Low levels of trace elements may affect cognitive functions, behaviour, social interaction, development and subsequently the quality of life.

The micronutrient status in 36 children with cerebral palsy, aged 1.5-17 years, was investigated by Hillesund et al. (23). In the Norwegian study the children completed a 4-day food diary, underwent an-

Table 1. Recommended/adequate dietary intake of vitamins

\begin{tabular}{|c|c|c|c|c|c|c|c|}
\hline Groups & Age/ Gender & $\begin{array}{l}\text { Thiamin } \\
\text { Vitamin B1 } \\
(\mathrm{mg})\end{array}$ & $\begin{array}{l}\text { Niacin } \\
(\mathrm{mg} \mathrm{NE})^{\mathrm{a}}\end{array}$ & $\begin{array}{c}\text { Folate } \\
(\mu \mathrm{g} \text { DFE })^{\mathrm{b}}\end{array}$ & $\begin{array}{l}\text { Vitamin } \\
\text { B12 }(\mu \mathrm{g})\end{array}$ & $\underset{(\mu \mathrm{g})^{\mathrm{c}}}{\text { Vitamin D }}$ & $\begin{array}{l}\text { Vitamin E } \\
\text { (mg alfa- } \\
\text { TCP) }{ }^{d}\end{array}$ \\
\hline \multirow{5}{*}{ Baby } & $0-6$ months & $0.2^{*}$ & $2^{*}$ & $65^{\star}$ & $0.4^{*}$ & $10^{*}$ & $3.7^{*}$ \\
\hline & 6-12 months & $0.3^{*}$ & $5^{*}$ & $80^{*}$ & $1.5^{\star}$ & $10^{*}$ & $5^{*}$ \\
\hline & $1-3$ years & 0.5 & 7 & 120 & 1.5 & 15 & 6 \\
\hline & $3-7$ years & 0.7 & 9.5 & 140 & 1.5 & 15 & 9 \\
\hline & 7 -10years & 0.9 & 11.5 & 200 & 2.5 & 15 & 9 \\
\hline \multirow{6}{*}{$\begin{array}{l}\text { Children/ } \\
\text { Adoles- } \\
\text { cents }\end{array}$} & Boys & & & & & & \\
\hline & $10-14$ years & 1.1 & 16 & 270 & 3.5 & 15 & 13 \\
\hline & $14-19$ years & 1.3 & 21 & 330 & 4 & 15 & 15 \\
\hline & Girls & & & & & & \\
\hline & $10-14$ years & 1.0 & 15 & 270 & 3.5 & 15 & 11 \\
\hline & $14-19$ years & 1.0 & 16 & 330 & 4 & 15 & 12 \\
\hline
\end{tabular}

$a_{-} N E$ - niacin equivalent; 1 niacin equivalent $=1 \mathrm{mg}$ of niacin or $60 \mathrm{mg}$ of tryptophan

${ }^{b}$ - DFE - dietary folate equivalent; $1 \mathrm{DFE}=1 \boldsymbol{\mu} \mathrm{g}$ of folate from food $=0.6 \mu \mathrm{g}$ of folate from food supplements or folate-rich foods

c - Vitamin D (cholecalciferol); $1 \mu \mathrm{g}$ of cholecalciferol $=40 \mathrm{IU}$ of vitamin D

${ }^{d}$ - TCP - alpha-Tocopherol equivalent; 1 alpha-Tocopherol equivalent $=1 \mathrm{mg}$-alpha-Tocopherol $=1.49$ IU Vitamin E

* Adequate intake

Table 2. Recommended/adequate dietary intake of minerals

\begin{tabular}{|c|c|c|c|c|c|c|c|}
\hline $\begin{array}{l}\text { Groups } \\
\text { Age/ Gender }\end{array}$ & $\begin{array}{l}\text { Calcium } \\
(\mathrm{mg})\end{array}$ & $\begin{array}{l}\text { Phosphorus } \\
\text { (mg) }\end{array}$ & $\begin{array}{l}\text { Magnesium } \\
(\mathrm{mg})\end{array}$ & $\begin{array}{l}\text { Iron } \\
(\mathrm{mg})\end{array}$ & $\begin{array}{l}\text { Zinc } \\
(\mathrm{mg})\end{array}$ & $\begin{array}{c}\text { Copper } \\
(\mu \mathrm{g})\end{array}$ & $\begin{array}{l}\text { Selenium } \\
(\mu \mathrm{g})\end{array}$ \\
\hline $0-6$ months & $210^{*}$ & $100^{*}$ & $30^{*}$ & $0.27^{*}$ & $2^{*}$ & $200^{*}$ & $10^{*}$ \\
\hline 6-12 months & $270^{*}$ & $270^{\star}$ & $80^{*}$ & $11^{\star}$ & $3^{*}$ & $400^{\star}$ & $15^{\star}$ \\
\hline $1-3$ years & 500 & 500 & 170 & 7 & 3 & 700 & 15 \\
\hline 3-7 years & 800 & 550 & 230 & 10 & 5 & 1000 & 20 \\
\hline $7-10$ years & 800 & 700 & 230 & 10 & 8 & 1000 & 35 \\
\hline \multicolumn{8}{|l|}{ Males } \\
\hline $10-14$ years & 1150 & 1150 & 300 & 11 & 9 & 1300 & 55 \\
\hline $14-19$ years & 1150 & 1150 & 300 & 11 & 11 & 1300 & 70 \\
\hline \multicolumn{8}{|l|}{ Females } \\
\hline $10-14$ years & 1150 & 1150 & 250 & 15 & 8 & 1100 & 55 \\
\hline $14-19$ years & 1150 & 1150 & 250 & 18 & 9 & 1100 & 70 \\
\hline
\end{tabular}


thropometric measurements and delivered blood for analysis of micronutrient concentrations. A low micronutrient intake was common both in children receiving $(n=16)$ and those not receiving nutritional supplements $(n=20)$. Approximately $50 \%$ of all children had a low iron intake. Among the non-supplemented children, $80 \%(16 / 20)$ had low vitamin $D$ intake, 65\% (13/20) - low niacin intake, 60\% (12/20) low iron intake, $45 \%$ (9/20) - low vitamin $\boldsymbol{E}$ intake, $40 \%(8 / 12)$ - low folate intake, and 35\% (7/20) - low calcium intake. The 16 supplemented children had higher mean intakes of most vitamins and minerals, but insufficient intakes of folates, iron, magnesium and vitamin $D$ were still observed in some patients. With regards to laboratory analysis, the children who received multi-vitamin supplements presented with higher concentrations of thiamine and cobalamin compared to those who did not receive supplements. Of all children, $22.2 \%(8 / 36)$ had low serum folates, $16.6 \%(6 / 36)$ had low serum vitamin $E, 13.8 \%(5 / 36)$ had depleted iron stores (ferritin $<12 \mu \mathrm{g} / \mathrm{L}$ ), $8.3 \%$ $(3 / 36)$ had low cobalamin levels and 5.5\% (2/36) had low zinc concentrations. Overall, the study found low dietary intakes and biochemical deficiency of several micronutrients in children with $\mathrm{CP}$, especially in those not receiving nutritional supplements.

In another more recent study, conducted by Kalra et al., the microelement levels in 50 children with CP (aged 2-12 years) and neurologically normal controls corresponding to age and gender were compared (24). Serum iron levels (12.6 \pm 5.9 and 20.9 \pm $3.3 \mu \mathrm{mol}$ at $\mathrm{CP}$ and controls, $\mathrm{p}<0.01)$, copper $(106.2 \pm$ $38.3 \mu \mathrm{g} / \mathrm{dl}$ in $\mathrm{CP}$ and $128.8 \pm 20.2$ in control, $\mathrm{p}<0.001$ ) and magnesium $(1.97 \pm 0.4$ in $\mathrm{CP}$ and $2.2 \pm 0.3 \mathrm{mg} / \mathrm{dL}$ in controls) were significantly lower in children with $\mathrm{CP}$ compared to the control group. Zinc levels were lower, although the difference was not statistically significant. The study confirmed that biochemical deficiency of microelements was common in children with $\mathrm{CP}$, indicating that dietary intake of vitamins and minerals was often too low to balance the needs of this population.

Additionally, children who are exclusively tubefed, may develop nutrient deficiencies, because enteral formulas provide adequate amounts of micronutrients only when volumes consumed meet their agerelated daily recommended intakes for energy. As seen above, many NDD children require lower energy intakes placing them at risk for low micronutrient intake (25).

Iron-deficiency anemia is a frequent complication in NDD children due to low iron intake. Papadopoulos et al. established high incidence of anemia in CP patients ( $\mathrm{n}=108$, aged 8-29 years). The research found out that $87 \%$ and $95.6 \%$ of patients on liquid diet were anemic and iron deficient, respectively (26). Characteristic oral manifestations of iron deficiency include mucosal pallor, atrophic glossitis, and candidiasis. They occur as a result of decreased levels of hemoglobin and oxygen in the tissues (27). General atrophy of the mucosa can also be noted, including that of the dorsal surface of the tongue. Such changes influence appetite and food choices. The tongue develops characteristic features of atrophic glossitis such as dark red patches and smooth quality of the papillae (28).

Selenium deficiency is another issue to be considered for NDD children who are receiving longterm enteral feeding, as some types of medical food products do not contain adequate selenium doses. Selenium is an important microelement and component of selenoproteins. A study conducted by Etani et al. analysed serum selenium levels of children and adolescents with neurological disabilities ( $n=71$, age range 7 months - 20 years) and/or intestinal dysfunction ( $\mathrm{n}=24$, age range 7 months - 20 years) who either received parenteral nutrition (PN) and/or enteral nutrition (EN) with either reduced or no selenium doses for more than 3 months. Twenty-eight patients (29\%) showed serum selenium levels below $4.0 \mu \mathrm{g} /$ $\mathrm{dL}$. Five patients whose serum selenium levels were below $2 \mu \mathrm{g} / \mathrm{dL}$ presented with various clinical manifestations, including hair browning $(n=5)$, macrocythemia $(n=4)$, nail whitening $(n=3)$ and cardiac dysfunction ( $\mathrm{n}=1)$ (29).

Carnitine deficiency is relatively common in children with epilepsy. Carnitine, a water-soluble quaternary amine, has important intracellular functions, but is only biologically active in the L-isoform. Approximately $75 \%$ of carnitine is obtained from the diet and the remainder from endogenous biosynthesis; carnitine deficiency can cause complications such as muscle weakness, cardiopathy and in severe cases also hypoglycemia, abdominal pain, vomiting 
and hepatomegaly. The risk factors for carnitine deficiency are reported to include multiple antiepileptic drug therapy (including valproic acid), young age $(<10$ years), neurological disability (intellectual disability, cerebral palsy and microcephaly), a diet deficient in meat and dairy products, tube feeding or parenteral nutrition (30-33).

Essential fatty acids (EFAs) are important for the normal development and functioning of the brain, retina and immune competent cells (34). The aim of a study, performed by Hals et al., was to evaluate if the dietary intakes and serum phospholipid concentrations of EFAs were adequate in a group of severely neurologically impaired children in an institution in the UK. A prospective study showed low dietary intakes of both n- 6 fatty acids (FAs) and n-3 FA. The serum concentrations of total n-6 FAs, linoleic acid and 22:6n-3 (docosahexaenoic acid) as proportions of the total serum phospholipid FA concentration were initially low. The serum concentrations of 20:3n-9 and 22:5n- 6 cholesterol, triacylglycerol, total saturated FA, total monounsaturated FA and apolipoproteins A-I and B were high compared with levels in a reference group of healthy children. Following supplementation with fish oil and soybean oil, the serum lipid profile approached normal.

\section{Nutritional Support}

Nutritional interventions are an essential part of the care of NDD children, which have complex and challenging requirements. Adequate nutritional support may restore linear growth, normalise weight, decrease irritability and spasticity, improve peripheral circulation, increase societal participation, hence improve overall health and quality of life.

With regards to specific nutrient requirements, unfortunately there are no international evidence-based guidelines for nutrient allowances specific for NDD children. DRVs for typically developing children can be used unless the child is severely undernourished.

An expert group of specialists in Nutrition and Dietetics from the National Center of Public Health and Analyses in Sofia has developed key aspects of dietary guidelines for neurologically impaired and mentally retarded children on the basis of literature review of the data on the problem (35). They have presented common nutrition requirements for NDD children and specific dietary guidelines for children with cerebral palsy, Down syndrome and epilepsy. The dietary recommendations have been considered with the DRVs for the Bulgarian population from 2005, Bulgarian Food Based Dietary Guidelines for children at different ages, published in 2008, and the ordinances of the Ministry of Health to establish healthy nutrition in schools (2009). In the recent years, a lot of new data on nutritional requirements of NDD children have been published, the DRVs for the Bulgarian population have been updated and will soon be published, new ordinances of the Ministry of Health with requirements for healthy nutrition in nurseries and kindergartens have been published and are currently being updated. The new information on the nutritional requirements of NDD children, the new DRVs for Bulgarians, and the current national strategies to improve nutrition of children should be considered.

\section{CONCLUSION}

Many nutritional problems in NDD children crucial for achieving the children's optimal growth and development - frequently remain overlooked in view of the primary concern about the underlying disease. However, overcoming these problems means reducing the child's neurological deficits and increases the ability to achieve the best possible development, lifespan and quality of life. Malnutrition, overnutrition as well as micronutrient deficiencies are common complications in NDD children, affecting their overall health and quality of life. Nutritionrelated issues are usually aggravated by the decline of motor skills and cognitive abilities. Nutrition evaluation, oral status, nutritional support as well as possible supplementation ought to be an integral part of the care for these children aimed at early detection of feeding problems. In order to ensure the success of interventions assisting NDD children, careful monitoring of their dietary and oral status should be done by a multidisciplinary team with the interaction of paediatritians, nutritionists, gastroenterologists, and neurologists, following a standardised approach now widely applied in European countries $(36,37)$. 
Ruzha Pancheva-Dimitrova, Albena Toneva, Miglena Georgieva et al.

\section{REFERENCES}

1. Penagini F, Mameli C, Fabiano V, Brunetti D, Dilillo D, Zuccotti GV. Dietary intakes and nutritional issues in neurologically impaired children. Nutrients. 2015;7(11): 9400-15. doi: 10.3390/nu7115469.

2. Dahl M, Thommessen M, Rasmussen M, Selberg T. Feeding and nutritional characteristics in children with moderate or severe cerebral palsy. Acta Pediatr. 1996;85(6):697-701.

3. Stallings VA, Charney FB, Davies JC, Cronk CE. Nutrition-related growth failure of children with quadriplegic cerebral palsy. Dev Med Child Neurol. 1993;35(2):126-38.

4. Krick J, Murphy PE, Markham JF, Shapiro BK. A proposed formula for calculating energy needs of children with cerebral palsy. Dev Med Child Neurol. 1992;34(6):481-7.

5. Rieken R, van Goudoever JB, Schierbeek H, Willemsen SP, Calis EA, Tibboel D, et al. Measuring body composition and energy expenditure in children with severe neurological impairment and intellectual disability. Am J Clin Nutr. 2011;94(3):75966. doi: 10.3945/ajcn.110.003798.

6. Walker JL, Bell KL, Boyd RN, Davies PSW. Energy requirements in preschool-age children with cerebral palsy. Am J Clin Nutr. 2012;96(6):1309-15. doi: 10.3945/ajen.112.043430.

7. Holenweg-Gross C, Newman CJ, Faouzi M, PoirotHodgkinson I, Bérard C, Roulet-Perez E. Undernutrition in children with profound intellectual and multiple disabilities (PIMD): its prevalence and influence on quality of life. Child Care Health Dev. 201;40(4):525-32. doi: 10.1111/cch.12085.

8. Kilpinen-Loisa P, Pihko H, Vesander U, Paganus A, Ritanen U, Mäkitie O. Insufficient energy and nutrient intake in children with motor disability. Acta Paediatr. 2009(98):1329-33. doi: 10.1111/j.1651-2227.2009.01340.x.

9. Russell SL, Psoter WJ, Charles GJ, Prophte S, Gebrian B. Protein-energy malnutrition during early childhood and periodontal disease in the permanent dentition of Haitian adolescents aged 12-19 years: a retrospective cohort study. Int J Paediatr Dent. 2010;20(3):222-9. doi: 10.1111/j.1365-263X.2010.01031.x.

10. Psoter W, Gebrian B, Prophete S, Reid B, Katz R. Effect of early childhood malnutrition on tooth eruption in Haitian adolescents. Communi- ty Dent Oral Epidemiol. 2008;36(2):179-89. doi: 10.1111/j.1600-0528.2007.00386.x.

11. Scardina GA, Messina P. Good Oral Health and Diet. J Biomed Biotechnol. 2012;2012:720692. doi: 10.1155/2012/720692.

12. Sheetal A, Hiremath VK, Patil AG, Sajjansetty S, Kumar SR. Malnutrition and its oral outcome - a review. J Clin Diagn Res. 2013; 7(1): 178-80. doi: 10.7860/JCDR/2012/5104.2702.

13. Agarwal PK, Agarwal KN, Agarwal DK. Biochemical changes in saliva of malnourished children. Am J Clin Nutr. 1984;39(2):181-4. doi: 10.1093/ ajcn/39.2.181.

14. González L, Nazario CM, González MJ. Nutrition-related problems of pediatric patients with neuromuscular disorders. P R Health Sci J. 2000;19(1):35-8.

15. Reinehr T, Dobe M, Winkel K, Schaefer A, Hoffmann D. Obesity in disabled children and adolescents. Dtsch Arztebl Int. 2010;107(15):268-75. doi: 10.3238/arztebl.2010.0268.

16. Tong HJ, Rudolf MC, Muyombwe T, Duggal MS, Balmer R. An investigation into the dental health of children with obesity: an analysis of dental erosion and caries status. Eur Arch Paediatr Dent. 2014;15(3):203-10. doi: 10.1007/s40368-013-0100-1.

17. Sfasciotti GL, Marini R, Pacifici A, Ierardo G, Pacifici L, Polimeni A. Childhood overweight-obesity and periodontal diseases: is there a real correlation?. Ann Stomatol (Roma). 2017;7(3):65-72. doi: 10.11138/ads/2016.7.3.065.

18. Hilgers KK, Akridge M, Scheetz JP, Kinane DE. Childhood obesity and dental development. Pediatr Dent. 2006;28(1):18- 22.

19. Buffart LM, van den Berg-Emons RJ, Burdorf A, Janssen WG, Stam HJ, Roebroeck ME. Cardiovascular disease risk factors and the relationships with physical activity, aerobic fitness, and body fat in adolescents and young adults with myelomeningocele. Arch Phys Med Rehabil. 2008;89(11):2167-73. doi: 10.1016/j.apmr.2008.04.015.

20. Rimmer JH, Rowland JL, Yamaki K. Obesity and secondary conditions in adolescents with disabilities: addressing the needs of an underserved population. J Adolesc Health. 2007;41(3):224-9. doi: 10.1016/j.jadohealth.2007.05.005.

21. Liou TH, Pi-Sunyer FX, Laferrere B. Physical disability and obesity. Nutr Rev. 2005;63(10):321-31. 
22. Dietary Reference Values for the Bulgarian population; Ordinance issued by the Ministry of Health). State Gazette (in press). [in Bulgarian]

23. Hillesund E, Skranes J, Trygg KU, Bøhmer T. Micronutrient status in children with cerebral palsy. Acta Paediatr. 2007;96(8):1195-8. doi: 10.1111/j.1651-2227.2007.00354.x.

24. Kalra S, Aggarwal A, Chillar N, Faridi MM. Comparison of micronutrient levels in children with cerebral palsy and neurologically normal controls. Indian J Pediatr. 2015;82(2):140-4. doi: 10.1007/ s12098-014-1543-z.

25. Piccol R, Gelio S, Fratucello A, Valletta E. Risk of low micronutrient intake in neurologically disabled children artificially fed. J Pediatr Gastroenterol Nutr. 2002;35(4):583-4.

26. Papadopoulos A, Ntaios G, Kaifa G, Girtovitis F, Saouli Z1, Kontoninas Z, et al. Increased incidence of iron deficiency anemia secondary to inadequate iron intake in institutionalized, young patients with cerebral palsy. Int J Hematol. 2008 Dec;88(5):495-497. doi: 10.1007/s12185-008-0191-3.

27. Baker RD, Greer FR, Committee on Nutrition American Academy of Pediatrics. Diagnosis and Prevention of Iron Deficiency and Iron-Deficiency Anemia in Infants and Young Children (0 -3 Years of Age). Pediatrics. 2010; 126(5):1040-50. doi: 10.1542/peds.2010-2576.

28. Bruch J, Treister N. Clinical Oral Medicine and Pathology. Humana Press: Springer. London; 2010.

29. Etani $Y$, Nishimoto $Y$, Kawamoto K, Yamada H, Shouji Y, Kawahara H, et al. Selenium deficiency in children and adolescents nourished by enteral nutrition and/or selenium-deficient enteral formula. J Trace Elem Med Biol. 2014;28(4):409-13. doi: 10.1016/j.jtemb.2014.09.001.

30. Castro-Gago M, Eiris-Punal J, Novo-Rodriguez MI, Couceiro J, Camiña F, RodríguezSegade S. Serum carnitine levels in epileptic children before and during treatment with valproic acid, carbamazepine, and phenobarbital. J Child Neurol. 1998;13(11):546-9. doi: 10.1177/088307389801301104.

31. Coulter DL. Carnitine deficiency in epilepsy: Risk factors and treatment. J Child Neurol. 1995; 10(Suppl 2):S32-9.

32. Fukada M, Kawabe M, Takehara M, Iwano S, Kuwabara K, Kikuchi C, et al. Carnitine deficiency: Risk factors and incidence in children with epi- lepsy. Brain Dev. 2015;37(8):790-6. doi: 10.1016/j. braindev.2014.12.004.

33. Verrotti A, Greco R, Morgese G, Chiarelli F. Carnitine deficiency and hyperammonemia in children receiving valproic acid with and without other anticonvulsant drugs. Int J Clin Lab Res. 1999;29(1): 36-40.

34. Hals J, Bjerve KS, Nilsen H, Svalastog AG, Ek J. Essential fatty acids in the nutrition of severely neurologically disabled children. Br J Nutr. 2000;83(3):219-25.

35. Duleva V, S Petrova, L Rangelova, E Chikova-Ischeber, K Vatralova. Key aspects of nutrition and dietary guidelines for neurologically impaired and mentally retarded children. Bulg J Public Health. 2012; 4:59-70

36. Gottrand M, Van Biervliet S, Velde SV, Gottrand F, Van Winckel M. Nutritional support in children with neurodevelopmental disabilities. Acta Gastroenterol Belg. 2013;76(3):329-34.

37. Kuper H, Nyapera V, Evans J, Munyendo D, Zuurmond M, Frison S, et al. Malnutrition and childhood disability in Turkana, Kenya: Results from a case-control study. PloS One. 2015;10(12): e0144926. doi: 10.1371/journal.pone.0144926. 